\title{
NEGOTIATING VULNERABILITY IN THE TRIGGER WARNING DEBATES
}

\author{
KATARIINA KYRÖL $\ddot{A}$
}

Cince around 2012, the use of trigger warnings or content warnings has $\checkmark$ spread all over the Internet and, to some extent, academic classrooms. Warnings about content that may be upsetting, offensive or that could trigger post-traumatic stress responses abound online, particularly in contexts where the addressed include people or groups deemed marginalised, disadvantaged or traumatised. Trigger or content warnings have most commonly been linked to online images and texts explicitly depicting sexual violence, mental illness, or sexist, racist, ableist, cis-sexist or heterosexist subordination.

These warnings have unsurprisingly elicited heated debate in academic circles: debate pieces appear on a regular basis in scholarly journals and blogs, such as Inside Higher Ed; the feminist journal Signs has assembled a digital archive of resources ${ }^{1}$ on trigger warnings; and the first book-length collection of essays about them, Trigger Warnings: History, Theory, Context, appeared in 2017 (Knox, 2017). The online magazine Slate declared year 2013 as the 'year of the trigger warning' (Marcotte, 2013). To a large degree, views have become polarised into 'against' and 'for' camps. At the same time, in many feminist, queer and anti-racist social media groups and discussion forums, the use of trigger warnings or content warnings has become standard practice and is taken as a necessary part of online discussion in spaces that are dedicated to fighting marginalisation and abuse based on gender, sexuality, ability, race or ethnicity. Trigger warnings have become expected and normalised in what are called safe - or safer - spaces online.

The point of departure for this chapter is my own initial doubt, even confusion, about trigger warnings. As a feminist media scholar long involved in interrogating 'bad feelings', and convinced they serve a purpose in 
challenging unjust power structures (Kyrölä, 2015; 2017), I felt such warnings ring disconcertingly of avoidance - and it seems that this point of departure is shared by most feminist, queer and critical race studies scholars who have participated in the public debate so far. However, something about the strong dismissal of trigger warnings bothered me as well, since they obviously serve an important purpose to those who request them, which led me to investigate the debate more thoroughly and to question my own initial reservations. This chapter thus examines first and foremost the online debates about trigger warnings or content warnings during the last few years, providing a mapping of the discourses around them, while another important aspect of the debate, namely the educational or classroom aspect, is not at the centre of focus. My aim here is not to argue against or for trigger warnings per se, but to invite readers to re-evaluate their own stances, as I have done, and understand what exactly we oppose or side with, when we oppose or side with trigger warnings. I do argue that it is essential to carefully analyse how trigger warnings are being used in various contexts and how they mobilise varying understandings of vulnerability, since they can be and are being used for completely oppositional political purposes - both to create alternative worlds where the marginalised set the pace, and to ridicule feminist, queer and anti-racist efforts.

The figure of the trigger warning currently seems to circulate most intensely in three key contexts: (1) feminist discussion forums and peer support communities where the use of trigger warnings or content warnings is a desired, required and normalised practice; (2) feminist, queer and antiracist academic critique of trigger warnings which emphasises the pedagogical value of negative affect and discomfort; and (3) anti-feminist online spaces where trigger warnings are seen as a condensation of how 'feminism has gone too far' in 'policing' what can and cannot be said. For feminist discussion forums, I use the rules for a Finnish closed Facebook group called the 'Laid-back Feminist Group' (in Finnish, 'Rento feministiryhmä') as an example, alongside some public online and academic debate pieces, including Sara Ahmed's. For the feminist, queer and anti-racist opposition of trigger warnings, I examine a selection of key texts by, for example, Jack Halberstam and Roxane Gay. For the anti-feminist ridicule of trigger warnings, I exemplify broader tendencies in the discourse through selected online articles. In each of these contexts, I aim to show that vulnerability is understood in somewhat different but overlapping ways: as a standpoint that both prohibits and enables; as a necessity to life that must be embraced; and as a paradoxical position where claims to power are made through claims of disempowerment.

In feminist and peer support discussion forums, trigger warnings have been seen as protection for vulnerable groups, an attempt to create safer 
spaces for those living with trauma or societal stigma. The intention of giving a trigger warning is usually to make apparent that the giver of the warning cares for the wellbeing of their audience members and wants to protect them from encountering potentially distressing content without warning or preparation. It is less important whether that content is actually experienced as distressing or traumatising by anyone, and more important to signal what the content may entail as well as perform the gesture of care. From this perspective, trigger warnings enable people to make informed choices about when, how or whether to engage, instead of being bombarded without warning with content that can produce emotional distress and therefore prohibit engagement (Carter, 2015; Cecire, 2014).

For the feminist anti-trigger warning public debaters, the same warnings have been seen as extensions of a culture of overprotection and paradoxical celebration of victimhood, focusing on individual psychology rather than oppressive structures. From the opposing perspective, the proponents of trigger warnings infantilise themselves and unwittingly pathologise the reading and watching practices of already marginalised groups, as if they were unable to take a critical distance from what they see, hear and read. Those opposing argue that trigger warnings can repress discussion and the representation of difficult or hurtful matters, when a feminist, queer and anti-racist stance to the world almost always means dealing with very hurtful matters - and hurt, pain and anger can have great value as feminist tools. Furthermore, the things that can trigger actual post-traumatic stress are usually unpredictable, such as a sound, a colour, or an arbitrary word or image, and even if triggers were known and obvious, avoidance is not effective treatment (Freeman et al., 2014; Friedersdorf, 2015; Gay, 2012; Halberstam, 2014a; 2017).

Even more recently, trigger warnings have become the latest favourite target of mockery for anti-feminists and some white liberal feminists alike, as well as for those opposing 'excessive political correctness' in the era of Donald Trump and the rise of right-wing nationalism in many European countries. In this context, trigger warnings have dismissively been called another symptom of 'generation snowflake' - the generation that came into adulthood in the 2010s, presumably more fragile and easily offended than the previous ones $(G Q, 2016$; Hartocollis, 2016). I bring this context into focus not to present it as a perspective among others but to examine how some of the language used in feminist contexts has been disconcertingly adopted into anti-feminist discourse. Scholars, activists and public debaters should be aware of the potential allegiances they may build, even if inadvertently, with anti-feminist voices, or white supremacist, trans-exclusionary feminist discourses. 
While the debate and the division between pro and anti camps have most forcefully taken place in the North American context, the same debates are also happening in other parts of the world like the Nordic countries, the location from which I am writing. Academic culture in the Nordic countries is different from the United States and Canada, for example in terms of the cost of education, but online cultures and practices of communication spread quickly across the world, like trigger warnings have. As many students and staff members participate in online communities, the online debates at the focus of this chapter cannot be held fully separate from educational contexts. Regardless of one's location and stance on trigger warnings, the question of how to deal with potential trauma and the varying backgrounds and identifications on university courses and online communities alike is a pertinent one.

Trigger warnings have been connected to an 'ethos of vulnerability' (Brunila and Rossi, 2017) in contemporary Western culture, where a shared vulnerability, in terms of shared experiences of trauma, oppression and victimhood, is underlined by the 'vulnerable' themselves as a key basis for claims to rights, recognition and voice. At the same time, and as pointed out in the introduction to this volume, vulnerability has a long history of being used as an authoritative concept, justifying the management and control of groups and populations from the 'outside' because they are deemed vulnerable. Both ways of employing vulnerability have further been linked to the rise of therapy culture where, it has been claimed, individual and psychoemotional approaches to trauma and oppression are easily prioritised over structural, political and policy efforts (Brown, 1995; Brunila and Rossi, 2017: 2-3).

In many ways, the debate about trigger warnings concretises key questions about vulnerability. This chapter asks how the varying uses of trigger or content warnings in online debates negotiate vulnerability and agency in relation to media content. Whose and what feelings matter in debates on trigger warnings? What bodies become vulnerable in various contexts, how is vulnerability understood in them, and how does it relate to agency - how subjects seem to gain and lose agency through vulnerability?

\section{RESPECTING VULNERABILITY: TRIGGER WARNING POLICIES IN FEMINIST ONLINE COMMUNITIES}

The background of trigger warnings has been identified as lying, on one hand, in online peer support and therapeutic forums and message boards for people with eating disorders, experiences of rape or sexual assault, or mental illness ever since the 1990s - members of these communities often 
(although not exclusively) being women or members of various marginalised groups (Washick, 2017). In the late 199os, trigger warnings also began to appear on feminist website message boards and blogs such as on xoJane and the Ms. Magazine forum, signalling care and safe spaces (Vigliano, 2014). In this sense, the history of trigger warnings can be connected to the simultaneous rise of cyber-feminist utopias about the Internet: how it could enable a different kind of world that would function based on the needs of the marginalised, and free us from identity-based hierarchies and oppression (for an overview see Bromseth and Sundén, 2011).

On the other hand, the background has been located in fan fiction (Lothian, 2016), where content warnings were also used in the 1990s. In fan fiction, however, the purpose of trigger warnings was not only to turn away those who did not want to encounter, for example, homosexual content or suicidal ideation, but also to lure in those who took pleasure in engaging with precisely that. The use of content warnings was community created and community driven, or, as Lothian (2016) phrases it, about queer worldmaking practices outside the world of the mainstream and more broadly acceptable pleasures. Into the 2010s, the terms 'content warning' or 'content note' have become more popular in fan fiction communities (Washick, 2017: 90), while the term 'trigger warning' has been saved more for explicitly shocking or violent content. As all these terms have become popularised, they are regularly used interchangeably.

In feminist, queer, anti-racist or disability activist groups and forums online, the rules and guidelines often direct participants in using trigger or content warnings. More often than not, these online spaces are moderated by a group of peers. The place of warnings is in the beginning of a post or a share, sometimes with empty space in between the warning and actual content, so that the content is hidden from appearing simultaneously with the warning. The aim is to create a non-discriminatory, safe or safer space for the participants - in other words, warnings can be seen as a part of such forums' feminist world-making practices, with the acknowledgement that the world at large is not and will not be as accommodating.

World-making, according to José Esteban Muñoz (1999: 195-6), is not only about alternative views of how the world could or should be, but about reordering, reshaping and decomposing, creating a space where different things are possible as compared to the 'real world' while using the real world as raw material. World-making practices are about potentiality, imagining what could be outside of the hegemonic order, building alternate realities. Trigger or content warnings, as they appear in feminist, queer and/ or anti-racist online forums and groups, participate in such world-making in the sense that they transform a world which functions on the terms of the privileged, where the hurt of the marginalised is constantly normalised 
and swept aside, into a world where the marginalised and the hurtfulness of structures and practices that subordinate them are highlighted and prioritised. Trigger or content warnings can be seen as one of the starting points for such world-making that ultimately aims to build an alternative reality, whether that is called a 'safe space' or something else.

For the purposes of this chapter, I received permission from the moderators of the Finnish Laid-back Feminist Group, a closed group on Facebook, to use their collectively created rules (a document within the group last edited 13 November 2017) as research material. ${ }^{2}$ I have been a member of the group for some time but have not participated beyond an infrequent 'like', only quietly observing. By applying to the group, members agree to follow the rules, which include not sharing content from the group to other websites or people outside the group. Feminist groups and publicly vocal feminists overall tend to be targets of intense anti-feminist trolling and harassment, thus this rule is meant to not only protect the privacy of the participants, but also protect them from online and offline attacks. Such policies are typical of closed feminist, queer, anti-ableist or anti-racist forums and groups, which poses challenges for studying online community formation in them (Association of Internet Research, 2012). The rules document, however, can be seen as an anonymous, collectively formed and continuously developing text which can exemplify some of the principles by which such feminist online groups can function, without specifically jeopardising the privacy or safety of any of its members. Nevertheless, the rules also acknowledge and warn members about sharing anything too personal, since the moderators cannot guarantee that no one in the group of thousands will share content elsewhere.

The group's name includes the adjective 'laid-back' because, as the rules document states, it is a group inclusive of people interested in learning about feminism who are not necessarily well-versed in feminist thought and discourse yet. The rules explain that inadvertent mistakes with language use or such are fine as long as members are willing to learn and correct themselves. That said, the rules also state that the group does not tolerate anti-feminist behaviour, which includes racism, ableism, cis-sexism, homophobia, and sexism, and if a member does not correct themselves after a warning, or does not follow the rules otherwise, the moderators will expel them from the group. Typical posts to the group include sharing links to and thoughts about media examples, political decisions, articles, or current events, as well as requests for advice in various situations.

The rules also require trigger or content warnings (with the abbreviation TW, CW or SV, the last one for the Finnish word 'sisältövaroitus', that is, 'content warning') before disturbing content. What counts as disturbing content is left open, but examples given include 'TW animal torture' and 
'TW violence against children'. Warnings can be requested by moderators or participants if the person posting did not include them, and the rules instruct that requests should be followed. In practice it is relatively common to see warnings before posts in the group, but many posts come without warnings, which means, after a while, that they were not requested either.

Notably, the 'Laid-back Feminist Group' functions through what the rules call 'the principles of safe space, where we prioritise listening to the oppressed. Before you comment, find out about your privileges'. The rules document also explains that moderators can close a comments section to people other than those oppressed by the matter at hand. I interpret this to mean, for example, disallowing white people from commenting on a racist incident, or prioritising trans voices when discussing cis-sexism. While the principle can raise questions about identity, such as definitions of a nonwhite identity and the fluidity of gender identification, it clearly recalls a standpoint feminist epistemological stance. Importantly, feminist standpoint theories (Collins, 2009; Harding, 1993) have demanded accountability for the specificity of knowledge producers' viewpoints, with a broader goal of challenging how the white, male perspective often cloaks itself as a 'universal' or 'neutral' perspective, dominating discussion and knowledge about marginalised groups from the 'outside'. Instead, standpoint feminisms place particular value on the experiences, voices and knowledge of subjugated groups and people broadly, and specifically about issues that concern them.

Similarly, in the Laid-back Feminist Group, what counts as vulnerability to various forms of oppression, a lack of a voice or a disadvantage in the world outside is turned into a prioritised voice, a demand for explicit recognition, respect and space. What is at stake, then, is not so much the individual possibility of being triggered into post-traumatic stress or anxiety, but the gesture by the community that it will function on the terms of those that are most fragile within the group and ask for care, that it will make space for the marginalised, the traumatised; that it will not allow the dominant to dominate, even if the dominant are the majority. Vulnerability becomes the basis of this standpoint feminist stance, which can be seen as a powerful world-making process. The risk is that it will inevitably estrange and exclude some people, groups and feminists, but that is the price for a collective space where the privileged do not speak for others but concretely step aside (Alcoff, 1991).

On the other hand, by setting the possibility of trauma as the norm and bottom line, this stance does place everyone within the group as vulnerable unless-otherwise-proved, implementing a kind of an equality of vulnerability. As Valeria Souza has argued in the blog post 'Triggernometry' (2014), trigger warnings can be seen as progressive from a disability perspective since they assume mental disability as the default state rather 
than able-mindedness or able-bodiedness. Angela Carter (2015) takes a similar perspective, framing trigger warnings as a question of access and making spaces accessible, not a question of safety or coddling all-toofragile egos. The issue of prioritising access for those potentially disabled by trauma connects back to the history of trigger and content warnings in the peer support and therapy-focused online groups. However, the Laidback Feminist Group does not assume or require any shared experiences or identity (such as 'survivor' or 'woman') from its participants in order to allow access, only a shared politics of intersectional feminism before anything else, as defined in the rules. These shared politics then lead to shared practices, including warnings.

At the same time, there can be 'dark' sides to this world-making and standpoint-based, default disability-assuming community building. For example, acceptable participation demands learning the rather specific language and discourse - including the correct use of trigger warnings - of feminist activism. Those who have not yet spent much time in feminist, queer and/or anti-racist contexts, and who have not taken gender studies classes or read feminist books, might not master the rules of the activist community quickly enough, and in those instances they risk being seen as unwilling to learn and are expelled. Learning the culturally and linguistically specific intersectional feminist discourse, and adopting the 'good feminist discussant' position and voice, may be more challenging and timeconsuming than the rule of expulsion-from-the-second-warning allows.

Furthermore, online discussions overall tend to quickly escalate into debates and even full-blown conflicts where affect runs intense (Paasonen, 2015). In order to keep the community functional and de-escalate a conflict, it might sometimes be necessary to shut down discussions either by removing a participant or closing a chain of comments, and the moderators of the Laid-back Feminist Group reserve the right to do this in the rules - a right which they have also exercised in the group. However, again, the wiggle room for marginalised subjects to express emotion is broader, according to the rules, than for the privileged: the rules forbid tone policing, which refers to intervening or policing the tone in which the oppressed talk about their own experiences of oppression. As an example, the rules mention a situation where an oppressed person is instructed to stay calm when they are being oppressed.

The discourse in an activist-oriented feminist community is not entirely similar to academic feminist discourse, at least not in the form familiar to me: despite my study and work history of two decades in feminist thought and theorising, the regular inclusion of content warnings and the typical ways of phrasing posts and comments took me some time to get used to and learn. What has to be noted here is that groups that function according 
to the principles of safe space similar to the Laid-back Feminist Group are already most likely to stay around for a while, which also means that the language of trigger and content warnings is already here to stay. Regardless of the reservations or the outright rejection of warnings by many academic feminists, which I will discuss in the next section, many feminist, queer and anti-racist scholars and students participate in, learn and want to follow the principles of similar activist groups and communities, and by doing so are passionately involved in alternative world-making. Trigger warnings in these spaces are not about the avoidance of difficult issues or creating a false sense of safety, but about showing care and recognition, and enabling access and informed engagement to potential and actual participants living with trauma.

Sara Ahmed (2014a), in an essay called 'Feminist hurt/feminism hurts' on her blog Feminist Killjoy and republished in this book, points out how the hurt expressed by those who have been traumatised by sexism or racism is often heard as imposition. This hurt, this imposition, can take the form of, for example, a trigger warning - which is then claimed to limit someone else's freedom to speak without one. But Ahmed turns the issue around: even if the requests or demands for warning may feel like an imposition or are turned into censorship, they are in fact not asking for limitations in the sense of less, but are about asking for more: more consideration for the context, the situatedness and the affective force of the material, and thus more complexity.

Yet, even if trigger warnings are understood as feminist standpoint practices, as radical alternative world-making, as an expression of the need to situate and complicate the affective force that the world can grab us through, the question remains about when and in what context to use trigger warnings. Their predecessors, like content labels on consumer products, began to be used in the United States in the 1930 s and since spread from food, alcohol and tobacco to cultural products, first in the form of film classification and age ratings (Souza, 2014). These labels and ratings, just like trigger warnings, seem to most often concern relatively easily identifiable things like (presumably) harmful substances, clear physical or emotional violence and eating disorders or suchlike, but problems arise immediately, when they are - or are not - used with finer and deeply normalised structures of oppression or marginalisation addressed, maintained or produced. For example, most contemporary media content and political decision-making functions according to the binary and heteronormative gender system, dividing all bodies into either men or women, and despite that system's violent reduction of all gender and sexual expressions and identifications into two categories, would it be necessary to add a trigger warning about cis-sexism and/or heterosexism to all examples of them when shared in a safe space or 
a classroom context? I will return to the question of when to use and not use trigger warnings in the next section, as the difficulty or impossibility of answering the 'when' question is one key motivation for those who choose not to give warnings.

Another difficulty arises from the possibility and reality that any feminist idea, principle or practice can (and often will) be taken out of its original context and used for purposes precisely opposite to what the idea or principle was created for (see Gill and Elias, 2014). Trigger warnings have also been de-rooted and appropriated to various contexts at the same time as claims of vulnerability have gained more ground as claims to rights and voice that cannot be silenced. In these cases, vulnerability becomes something that anyone experiencing hurt can 'claim' for themselves, whether that hurt derives from the momentary loss of structural privilege or from structural oppression. Therefore, it has become possible for Trump supporters to ask for safe spaces on liberal campuses (Hartocollis, 2016), or Christian conservative students in the United States to ask for (and receive) a trigger warning for (or be excused from engaging with) sexually explicit content or homosexual themes on university syllabi through claiming vulnerability to religion-based oppression, when their religious beliefs are against homosexuality (Cooper, 2014; Levinovitz, 2016).

The language of triggers has furthermore been adopted in transexclusionary feminist demands to exclude transwomen from 'women-only safe spaces' because even the potential presence of a penis can, they claim, be triggering for rape survivors - who, within this logic, can only be cisfemale (Phipps, 2016). The discussion becomes entirely something else and shockingly violent, when the very existence of a person and a gender identity becomes named as 'triggering, when a body, not a text or image, becomes a 'trigger' by its mere presence. Such practices stand in radical contrast to the principles of safe space in communities such as the Laid-back Feminist Group, which explicitly prohibits trans-exclusionary feminist practices within its discussions. This only goes to show how the language of triggers can be used for entirely different, and indeed oppositional, purposes.

\section{EMBRACING VULNERABILITY: ACADEMIC FEMINIST ANTI-TRIGGER WARNING ARGUMENTS}

The feminist anti-trigger warning arguments have mostly been made in the context of higher education, touching upon the use of such warnings online and in activist communities only in passing. The majority of such writing and engagement has simultaneously expressed compassion and concern for students struggling with racist, sexist, heterosexist and cis-sexist or ableist 
marginalisation, as well as mental health issues and sexual harassment and violence (Freeman et al., 2014; Gay, 2012; Halberstam, 2014a; 2014b; 2017). Next, I want to look more closely at some key arguments of the anti-trigger warning camp. They are, first, the unpredictability of how trauma and posttraumatic stress disorder (PTSD) work; second, the difficulty or impossibility of deciding when to warn and when not to in terms of media material; and third, the value of staying with discomforting and overwhelming - or perhaps especially discomforting and overwhelming - reactions and affect.

In her essay 'The safety of illusion/the illusion of safety' (2012), the wellknown black feminist public intellectual Roxane Gay argues that there is no trigger warning that could guarantee anyone's safety, that they are about an illusion of safety that may function contrary to its purpose. Gay's essay is spotted with sentences that begin 'when', such as 'when I smell Polo cologne' and 'when someone comes up behind me unexpectedly', signalling moments that function as triggers for her, as she has publicly relayed her own complicated struggles with PTSD from having been gang-raped as a young girl. According to Gay, there can never be trigger warnings for all that might trigger a post-traumatic stress reaction for a rape or sexual assault survivor, because such triggers are unpredictable, even to those experiencing them. Anything can be a trigger for someone - furthermore, trigger warnings can also make things more appealing, just like age restrictions for media content can make it all the more attractive for some. However, Gay also states that, regardless of how ineffective and impractical she considers trigger warnings, the illusion of safety they produce can be powerful and important, even if it is an illusion. The voice she uses is that of someone who has much experience of becoming triggered, a voice from the 'inside'; an empathetic, even if suspicious, voice that unequivocally argues that vulnerability will always be a part of life and corporeality as well as media consumption, and that pain has value, even if a cost too.

Trauma therapists, similarly, have argued that PTSD cannot be treated effectively with the avoidance of possible triggers, which trigger warnings might enable - if such triggers can even reliably be identified (Waldman, 2016). A group of prestigious gender, queer and critical race studies faculty (Freeman et al., 2014) also point out in their statement about why they see trigger warnings as flawed that university faculty are not therapists nor trained in treating PTSD. Therefore, resources should be directed to offering sufficient professional care to students who suffer from mental health issues and disabilities, since trigger warnings can never substitute treatment.

Here, a differentiation between a trigger warning and a content warning becomes important, although their meanings slide into each other after much interchangeable use. The term 'trigger' connects particularly to PTSD and the sudden, potentially violent and disabling reactions to 'triggers' like 
images, sounds, smells, words, and touch that may recall a traumatic event. Also, the argument against trigger warnings from a PTSD perspective is, like Gay's, highly convincing - after all, it does seem futile to try to fight complex trauma with the simple addition of the letters 'TW'. However, it seems that in their contemporary activist uses, trigger or content warnings are not really used with post-traumatic stress disorder sufferers in mind more so, the use of terms like 'trigger' and PTSD in these contexts appears to lend the warnings more legitimacy in the therapy cultural context. When warnings are seen first and foremost as a call for recognition of and care for the suffering that racist, sexist, heterosexist and cis-sexist hegemonic structures produce for members of subordinated groups, then the argument against trigger warnings as ineffective treatment loses much of its meaning.

The argument indeed recalls the critiques that feminist consciousnessraising and political therapy groups in the 1960s and 1970s faced in terms of the investment in the personal as political. Carol Hanisch (1969), who is usually credited with the well-known feminist slogan, actually argued that dismissing such groups as therapy or focused on personal problems is to dismiss their political dimension, since they do not aim to solve personal problems by offering personal solutions. Their focus is on seeing both problems and solutions as political, as in having to do with oppressive structures, not individual successes or failures in dealing with them. Similarly, trigger and content warnings in groups such as the Laid-back Feminist Group are not so much for those who suffer personally or are diagnosed with PTSD, but those who are structurally oppressed and carry the trauma of that oppression.

The more important question thus becomes: what counts as content that warrants a warning in a world that is so thoroughly structured by unjust norms and hierarchies - hierarchies that feminist, queer and critical race studies teachers and online communities are dedicated to revealing and unravelling? Jack Halberstam, in his several texts about trigger warnings (2014a; 2014b; 2017), has addressed precisely this difficulty of when and where to warn as a key reason why trigger warnings are, according to him, counterproductive, as they seem to set representations and practices in a flawed hierarchy of oppressiveness based on affective reaction. In the essay 'Trigger happy' (2017), republished in this book, Halberstam gives the example of how silence and invisibility - the complete lack of representation - can potentially be just as traumatising or discomforting as an explicit representation, such as the exclusion of issues of race, gender or class altogether from philosophy or political science classes. Another example that Halberstam discusses is a course he taught on the Holocaust, where he showed the film Nuit et brouillard [Night and Fog] (1955, dir. Alain Resnais), with brutal imagery of dead, naked, piled-up bodies, to the students' shock, 
while they were captivated by and wanted to see more of Triumph des Willens [The Triumph of the Will] (1935, dir. Leni Riefenstahl), a film specifically meant to make Nazism aesthetically and ideologically appealing through veiling it in visual pleasure. Indeed, it is of essential importance to question why seemingly inconspicuous and pleasurable to watch content usually does not warrant a warning, even if it is ideologically deeply disturbing, just as it must be asked why the lack of representation does not warrant a warning. However, while Halberstam considers this an example of why trigger warnings do not make sense overall, I suggest that the difficulty of deciding 'when' could just as well necessitate more questioning, careful contextualisation and collective consideration of why, when and if to warn.

Indeed there was a time when feminist, queer and critical race studies scholars were much more worried about the treacherousness of pleasure than about pain and hurt. For example, in the 1980s Mary Ann Doane (1982) interrogated the ways Hollywood cinema constructs the female body as an idealised and pleasurable spectacle. Through a recognition and pull of similarity, the female spectator has no choice but to over-identify with the image, unless she fully rejects it. The reward is pleasure and idealisation, and the price is submission to a patriarchal structure of gendered subordination where women are reduced to beautiful surfaces. According to feminist psychoanalytical film theory approaches, such as Doane's, it is pleasure that makes spectators unwittingly and unavoidably vulnerable and open to identifying with power structures that will keep them subordinated, whereas in the pro-trigger warning arguments, subordination is often taken up as something that is easily recognisable in representation and discourse through viewers' and readers' upset reactions.

On the other hand, one of the key critiques directed at feminist psychoanalytical approaches is that they have often assumed a rather stable similarity between the gendered spectator and the image of a gendered human form to be a prerequisite for the 'suction' into the image. The impossibility of predicting reactions based on such an assumed similarity is also one of the key feminist anti-trigger warning arguments: that it is impossible to say, for example, that seeing explicit racism is more triggering than silence about racism for those that live with the trauma of everyday racism, or that every black person would be equally upset or anxious about a representation of racism. Such 'competitions' of what kind of content wounds more, or who are the ones most vulnerable to potentially triggering content, come up easily when trigger warnings become standard practice, Halberstam (2017) points out. On the other hand, these 'competitions' that Halberstam critiques are also direly necessary in order to not accept or condone the claims to victimhood by members of structurally privileged groups, such as white men in right-wing and white nationalist movements habitually do, 
or to not claim a false symmetry between all levels and forms of structural subordination, for example that between transwomen of colour and white cis-women.

I tried to tackle these complications around shock and normalisation, pleasure and trauma, when to warn and when not to, in my own teaching in Finland in 2015 on a course about media and the body. One of the course themes was trigger warnings and sexually violent content (see also Kyrölä, forthcoming). The students read blog texts advocating for and against trigger warnings, as well as the main points of an empirical study by Martin Barker et al. (2007), who had been commissioned by the British Board of Film Classification (BBFC) to study audience reactions to five films that depict sexual violence. One of those films was À ma soeur! (Fat Girl, France, 2001, dir. Catherine Breillat), which we watched for class. The students were then asked to compare their own reactions and reflections to those of Barker and his group's respondents, as well as form an opinion of whether trigger warnings or censorship were necessary in relation to the film.

Fat Girl ends in a notorious rape scene that has been the film's most debated feature, and has been censored in some countries. In this scene, a twelve-year-old girl, Anaïs (Anaïs Reboux), is raped in the woods by a nameless male attacker after he has brutally killed her sister with an axe and strangled her mother at a rest stop by a highway. The students were given access to the censored version of the film, and separately to the rape scene (about five minutes long) - with my explicit warning that the scene would include rape. I did not require them to watch it, but all of them chose to do so. However, instead of the rape scene, many of the students wanted to discuss the more insidious sexual abuse elsewhere in the film, particularly a lengthy (twenty-five-minute) scene earlier in the film where a young man pressures Anaiis' fifteen-year-old sister Elena (Roxane Mesquida) to have intercourse with him with Anaiis in the room. To the students, it seemed hypocritical that the scene which directly portrayed rape was censored and accompanied by warnings, while the scene about sexual abuse was not. Many reviews of the film even discussed the lengthy scene as one of seduction, not abuse. The students broadly agreed that the film was very discomforting to watch overall, but that was precisely how it should be, given its topic of sexual abuse and gendered sexual agency.

Today, in the post-\#MeToo world, I would very likely make the choice to give a content warning about the whole film, not only the explicit rape scene, and the possibility for an alternative assignment. However, this example testifies to how the lines of what warrants a warning - or when, or if - are necessarily changing according to how gendered, racialised and sexual power structures shift in culture and society. Should we include a trigger warning or content warning about sexual abuse for all films or other 
content that include a scene of heterosexual 'seduction' or a woman reluctantly 'giving in to desire' - one of the most common tropes representing female desire according to Linda Williams (1989)? That might have seemed ridiculous only a little while ago, but no more, as sexual harassment and the blurry lines of consent and abuse around sex have finally become highprofile topics.

The feminist anti-trigger warning arguments, or perspectives suspicious of the effectiveness and purpose of trigger warnings, seem to have one thing in common: they place great value on feelings of discomfort and even hurt as necessary parts of pedagogy and learning, and they take vulnerability as an unavoidable condition of embodied life, which should be embraced rather than rejected. This view of vulnerability, that can be characterised as phenomenological and ontological (Butler, 2004; Shildrick, 2002), does still take into consideration the ways in which the basic human and non-human openness to the world, the porousness and fragility of corporeality, are distributed unevenly between groups of bodies. This allows some groups to maintain the privilege of relative safety, despite it being a fragile illusion, while others are deemed exceptionally vulnerable and thus disposable or subjected to paternalistic management measures. The feminist anti-trigger warning stance sees warnings as a measure to create such an illusion of safety, which in this logic easily translates into a paradoxical position of privilege that students who are unwilling to be uncomfortable exercise. Black feminist professor Brittney Cooper (2014), in her argument against trigger warnings, suggests that being and staying comfortable is actually at odds with the very foundation of what it means to get an education, especially in the gender and critical race studies classroom. Cooper also sees this tendency as understandable in the context of a broader results and testfocused neoliberal educational culture and the financial pressures to get a college degree, regardless of what one actually learns in the process. The more effective strategy for changing the world, for Cooper as well as other feminist trigger warning critics, is to stay with the discomfort and deal with vulnerability even when it is almost unbearable, since it will become more endurable through learning feminist tools of analysis and critique.

In my teaching and research I have also studied and argued for the ethical and political value of feeling bad, uncomfortable, guilty, disgusted and angry when engaging with problematic media materials from a feminist, queer studies and critical race studies perspective, a stance that has long roots in these critical traditions (Kyrölä, 2015; 2017). I no longer think, though, that the use of trigger or content warnings would be at odds with such an approach which embraces vulnerability and so-called bad feeling. Many proponents of trigger warnings in fact argue that such warnings can be a prerequisite for the ability to engage with discomfort and bad feeling, 
since without warning that ability might be compromised (Carter, 2015). But it matters deeply who or what instance asks for a warning and in what context, as trigger warnings can surely become a tool of condescending, paternalistic control, just as their refusal and the suggestion to just 'suck it up' and take a critical distance can seem condescending and paternalistic.

\section{MOCKING OR APPROPRIATING VULNERABILITY: ANTI-FEMINIST ANTI-TRIGGER WARNING DISCOURSE}

The most disconcerting way in which trigger warnings have been mobilised today concerns the anti-feminist stances which see them as ridiculous symptoms of a culture of victimhood, or how 'whiny', overly protectionoriented and narcissistic young people, particularly feminist and queer youth and students of colour, have become. For example, the magazine $G Q$ (2016) ridicules 'Millennials' who have become 'Generation Snowflake: a collective that quivers at the slightest breeze and dissolves at the slightest upset.' The deployment of the term 'Generation Snowflake', or 'snowflake' more broadly, appears regularly in distinctly anti-feminist contexts, where complaints against using insensitive words, such as racist or sexist slurs, are seen to limit freedom of speech. The $G Q$ article is accompanied by an image of students of colour protesting with a sign saying 'Decolonise Education: Rhodes Must Fall', in reference to the student-led campaign which started in South Africa to remove statues of white imperialist oppressors from university campuses, and to produce cultural countermemory (see e.g. Bosch, 2016). The article asks where to draw the line - if the presence of imperialist oppressors is perceived as triggering, should the faces of all oppressors, like Hitler and Mussolini, be removed from books and museums too? The image seems an odd choice, since the Rhodes Must Fall campaign never actually utilised the language of triggering or warnings, but the campaign has repeatedly been taken up as an example of the 'cult of the victim' (O'Neill, 2015). 'Snowflakes' are rarely white in this discourse that mocks trigger warnings, which points towards its investment in white supremacy and white patriarchal sense of disenfranchisement. The vulnerability of easily triggered 'snowflakes' is seen as a false claim of victimhood, which has the barely hidden purpose of gaining power and unwarranted privilege through sinister calls for compassion and care.

Those feminists who mobilise the problematic figures of the 'snowflake' and 'overly fragile students' in debating trigger warnings should seriously reconsider their use of such figures, since they can easily play into the antifeminist and white supremacist discourses that ridicule and seek to silence marginalised voices seeking change. Feminists opposing trigger warnings 
may want to be extra careful about the tone with which they discuss trigger warnings and those who request them, if they want to avoid siding with anti-feminist and white supremacist voices. Disquietingly, the feminist and anti-feminist critics of trigger warnings often share a humorous and mocking tone, perhaps accompanied with a meme or a text about being 'triggered by trigger warnings', popular in the anti-feminist blogosphere, but found in Halberstam's first blog post about trigger warnings too (2014a). This tone leaves the proponents of trigger warnings with no other role than that of feminist killjoy.

The white, masculinist anti-feminist anti-trigger warning stance intersects with the feminist anti-trigger warning stance also in the claim that this is an issue of generational differences, and that the previous generation was not as fragile (Halberstam, 2014a). Transfeminist writer and activist Julia Serano (2014) has indeed critiqued Jack Halberstam for too broad strokes and simplifications about feminist generations and for dismissing the younger activists for their oversensitivity and 'killjoy' or 'no fun' approaches. Serano argues that the activist strategies of previous generations often cease to work for the next, as the world has also changed drastically through social media. However, women and marginalised people who 'take things too personally' have also been around as figures of concern for decades, and the vocal worry about complainers turning the nation into a narcissistic well of oversensitivity is not something that characterises our time alone. For example, Imogen Tyler (2007) has pointed out that the narcissistic, self-centred feminist was in fact already a popular figure in the anti-feminist discourses in the 1970s and 1980s - and then, too, it was argued that such feminists are a part of a new, broader narcissistic malaise.

The feminist-mocking anti-trigger warning discourse has even adopted other arguments of the feminist anti-trigger warning camp. Another one is the approach to vulnerability and the inevitable cruelty of this world: that vulnerability is an ontological condition of existence, and in order to be able to live in the world as a mortal who will experience hurt, one must learn tools to 'suck it up'. Yet a further similar argument concerns the difficulty of drawing the line between when to warn and when not to, and what to show and what not to: both feminist and anti-feminist critics of trigger warnings agree that the line is impossible to draw.

However, the important difference is that, in the anti-feminist discourse, there is very little if any recognition of the political dimensions of vulnerability and the ways it becomes asymmetrically lived, managed, assigned and made palpable for various groups in global and local power structures. The subordinated groups that ask for trigger warnings are seen as ridiculous, their requests for recognition of their suffering unjustified and whiny, claiming that those who do not 'submit' to such requests are victims of 
harassment and falsely accused of racism or sexism. The feminists opposing trigger warnings disagree with trigger-warning proponents about the effectiveness of warnings, but agree about the existence of injustices and the goal of a world free of oppression. The anti-feminists opposing warnings see no real or deep structures of oppression, just a world that is an equally cruel and trying place for all. However, as Marilyn Frye (1983) stated in the 1980 os in response to anti-feminist claims that everyone suffers, and thus everyone is oppressed: 'This is nonsense. Human beings can be miserable without being oppressed, and it is perfectly consistent to deny that a person or group is oppressed without denying that they have feelings or that they suffer.

Paradoxically, trigger warnings themselves can also be used for antifeminist, racist and transphobic purposes that completely defy their original purpose, as mentioned in this chapter in relation to trans-exclusionary feminists. Freeman et al. (2014) argue that the complaints made about the lack of appropriate trigger warnings tend to be disproportionately directed towards faculty who teach critical race studies and feminist and queer theory. The material that educators in these critical fields ask students to engage with is most often upsetting by nature, and the ways we ask students to engage with that material is meant to unsettle normative, ordinary and perhaps comfortable ways of thinking. The irony is that trigger warnings are not asked - or expected - from people or groups that are already assumed to not care. They are asked of those who are assumed and expected to care, but the risk is that disagreement about how to show that care can result in divisiveness, even the adoption of anti-feminist discursive figures like 'snowflakes' or (other) feminists as narcissists.

\section{VULNERABLE WORLD-MAKING}

Vulnerability has, in the contexts discussed above, been understood as a structurally produced disadvantage that can be countered by a standpoint epistemological privileging of the voice of and care for the vulnerable; an ontological, necessary condition which should be explored and embraced head on in order to fight the way it is used for managerial politics; or a false claim of disempowerment and thus a false attempt to gain more power.

Two of the contexts I have discussed, the feminist trigger warnings policies and the feminist anti-trigger warning arguments, can be seen to participate in feminist world-making, following Muñoz's (1999) reflections on queer of colour performance as world-making - even if they suggest different routes and strategies. For those feminists who support trigger warnings, their absence produces a barrier or a wall that restricts or prevents their 
mobility (Ahmed, 2014b), or the mobility of those they want to show they care about. Their alternative world-making, enabled by trigger warnings, concerns a world where the marginalised could roam free without the barrier of fear, without constantly, accidentally running up against the wall of sexism, racism, cis-sexism or heterosexism. In this sense, groups like the Laid-back Feminist Group in part recall the feminist separatist groups of the 1970 in terms of alternative world-making and rules different from those of the 'outside' world. For feminist separatist groups, the best way to not only imagine but practice how to build a world free from white capitalist patriarchal oppression was to detach from it, create barriers that shield from it, break down everyday practices that define it, and exclude people who benefit from it (Valk, 2008).

The anti-feminist and white supremacist voices that oppose trigger warnings do not see or recognise walls or structural oppression in the world, but prioritise an equally shared, ontological vulnerability and suffering. For them, the world is an even playing field, and trigger warnings are yet another symptom of how 'whiny' people of colour, queers and feminists are in the face of unavoidable pain. This discourse includes a paradox though, since trigger warnings also get to represent walls that could restrict the movement and 'free speech' of the privileged, the claimed 'victims' of trigger warnings. One of the most disconcerting findings of my mapping of the discourses around trigger warnings is the extent of how much feminist anti-trigger warning language intersects with and is co-opted by anti-feminist and white supremacist contexts.

The feminists who oppose warnings, just like those who support them, see that the world, as it is now, is structured by barriers that produce marginalisation and privilege, distributing vulnerability asymmetrically. However, their suggestion is to push up against such barriers and trust that this pushing will not break those who push, instead of turning away from the barriers through practices such as warnings. But feminist support for warnings is not quite the opposite of pushing either, as evidenced by the fierce opposition that trigger warnings have encountered: it takes another kind of pushing to make space for and turn towards an alternative world. The difference is perhaps rather the difference between pushing with one's back and pushing head first - a matter of which direction you face. The advantage of a community facing inwards while pushing is that it then might be easier to glimpse an alternative, although fragile and complicated, world where the currently marginalised have the power, where their voices are privileged, and where gestures of care towards them abound. It is important, however, that both 'sides' of the debate recognise the value and effort of how the other side pushes, since the alternative worlds we long to inhabit may not be that different. 


\section{NOTES}

1 The Signs digital archive on trigger warnings is available at: http://signsjournal. org/currents-trigger-warnings/\#digitalarchive (accessed 4 June 2018).

2 I contacted the moderator who created the document in November 2017, explained the purposes of the research and the article, and requested permission to use the rules document in my research, with the understanding that the moderators would check and, if needed, correct the article before publication. The moderators gave permission for this. In early February 2018, I sent a preproofread article draft for them to check, and on 8 February they gave permission to move forward with the publishing process without corrections.

\section{REFERENCES}

Ahmed, S. (2014a). 'Feminist hurt/feminism hurts', Feminist Killjoys (21 July), https://feministkilljoys.com/2014/07/21/feminist-hurtfeminism-hurts (accessed 17 December 2017).

Ahmed, S. (2014b). 'Atmospheric walls', Feminist Killjoys (15 September), https:// feministkilljoys.com/2014/o9/15/atmospheric-walls (accessed 4 February 2018).

Alcoff, L. (1991). 'The problem of speaking for others', Cultural Critique, 20, pp. 5-32.

Association of Internet Research (2012). Ethical Decision-Making and Internet Research, http://aoir.org/reports/ethics2.pdf (accessed 4 June 2018).

Barker, M., E. Mathijs, J. Sexton, K. Egan, R. Hunter and M. Selfe (2007). Audiences and Receptions of Sexual Violence. London: British Board of Film Classification.

Bosch, T. (2016). 'Twitter activism and youth in South Africa: The case of \#RhodesMustFall', Information, Communication E Society, 20:2, pp. 221-32.

Bromseth, J. and J. Sundén (2011). 'Queering internet studies: Intersections of gender and sexuality', in M. Consalvo and C. Ess (eds), The Handbook of Internet Studies. Chichester: Wiley \& Blackwell, pp. 270-30o.

Brown, W. (1995). States of Injury: Power and Freedom in Late Modernity. Princeton: Princeton University Press.

Brunila, K. and L.-M. Rossi (2017). 'Identity politics, the ethos of vulnerability, and education', Educational Philosophy and Theory, 50:3, pp. 287-98. https://doi.org/ 10.1080/00131857.2017.1343115.

Butler, J. (2004). Precarious Life: The Powers of Mourning and Violence. London: Verso.

Carter, A. (2015). 'Teaching with trauma: Trigger warnings, feminism, and disability pedagogy', Disability Studies Quarterly, 35:2, http://dsq-sds.org/article/view/ 4652/3935 (accessed 17 December 2017).

Cecire, N. (2014). 'On the "neoliberal rhetoric of harm"' (7 July), http://nataliacecire. blogspot.fi/2014/o7/on-neoliberal-rhetoric-of-harm.html (accessed 17 December 2017).

Collins, P. H. (2009 [1990]). Black Feminist Thought: Knowledge, Consciousness and the Politics of Empowerment. New York: Routledge.

Cooper, B. (2014). 'No trigger warnings in my class: Why you won't find them on my syllabi', Salon.com (20 May), www.salon.com/2014/05/20/no_trigger_warnings_ in_my _class_why_you_won\%E2\%80\%99t_find_them_on_my_syllabi/ (accessed 17 December 2017). 
Doane, M. A. (1982). 'Film and the masquerade: Theorising the female spectator', Screen, 23:3-4, pp. 74-87.

Freeman, E., B. Herrera, N. Hurley, H. King, D. Luciano, D. Seitler and P. White (2014). 'Trigger warnings are flawed', Inside Higher Ed (29 May), www.insidehighered. com/views/2014/05/29/essay-faculty-members-about-why-they-will-not-usetrigger-warnings (accessed 14 January 2018).

Friedersdorf, C. (2015). 'The rise of victimhood culture', The Atlantic (11 September), www.theatlantic.com/politics/archive/2015/09/the-rise-of-victimhood-culture/ 404794 (accessed 17 December 2017).

Frye, M. (1983). 'Oppression', in The Politics of Reality: Essays in Feminist Theory. Trumansburg: The Crossing Press, https://feminsttheoryreadinggroup.wordpress. com/2010/11/23/marilyn-frye-the-politics-of-reality-oppression (accessed 4 February 2018).

Gay, R. (2012). 'The illusion of safety/the safety of illusion', The Rumpus.net (27 August), http://therumpus.net/2012/08/the-illusion-of-safetythe-safety-of-illusion (accessed 17 December 2017).

Gill, R. and A. S. Elias (2014). "Awaken your incredible”: Love your body discourses and postfeminist contradictions', International Journal of Media and Cultural Politics, 10:2, pp. 179-88.

$G Q$ (2016).'Millennials:Stopbeingoffendedby, like,literallyeverything', $G Q(12$ August), www.gq-magazine.co.uk/article/millennials-created-generation-snowflake (accessed 17 December 2017).

Halberstam, J. (2014a). 'You're triggering me! The neoliberal rhetoric of harm, danger and trauma', BullyBloggers (5 July), https://bullybloggers.wordpress.com/ 2014/07/05/you-are-triggering-me-the-neo-liberal-rhetoric-of-harm-dangerand-trauma (accessed 17 December 2017).

Halberstam, J. (2014b). 'Triggering you, triggering me: Making up is hard to do', BullyBloggers (15 July), https://bullybloggers.wordpress.com/2014/o7/ 15/triggering-me-triggering-you-making-up-is-hard-to-do (accessed 17 December 2017).

Halberstam, J. (2017). 'Trigger happy: From content warning to censorship', Signs: Currents, http://signsjournal.org/currents-trigger-warnings/halberstam (accessed 17 December 2017).

Hanisch, C. (1969). 'The personal is political', in Writings by Carol Hanisch, www. carolhanisch.org/CHwritings/PIP.html (accessed 3 February 2018).

Harding, S. (1993). 'Rethinking standpoint epistemology: What is "strong objectivity"?', in L. Alcoff and E. Potter (eds), Feminist Epistemologies. New York and London: Routledge, pp. 49-82.

Hartocollis, A. (2016). 'On campus, Trump fans say they need "safe spaces"', New York Times (8 December), www.nytimes.com/2016/12/o8/us/politics/political-divideon-campuses-hardens-after-trumps-victory.html (accessed 17 December 2017).

Knox, E. J. M. (2017). 'Introduction: On trigger warnings', in E. J. M. Knox (ed.), Trigger Warnings: History, Theory, Context. Lanham: Rowman \& Littlefield, pp. xiii-xxi.

Kyrölä, K. (2015). 'Toward a contextual pedagogy of pain: Trigger warnings and the value of sometimes feeling really, really bad', Lambda Nordica: Nordic journal on LGBTQ studies, 1, pp. 131-44.

Kyrölä, K. (2017). 'Feeling bad and Precious (2009): Black suffering, white guilt, and intercorporeal subjectivity', Subjectivity, 10:3, pp. 258-75. 
Kyrölä, K. (forthcoming). 'Squirming in the classroom: Fat Girl (2001) and the ethical value of extreme discomfort', in N. Baer, M. Hennefeld, L. Horak and G. Iversen (eds), Unwatchable. New Brunswick: Rutgers University Press.

Levinovitz, A. (2016). 'How trigger warnings silence religious students', The Atlantic (30 August), www.theatlantic.com/politics/archive/2016/o8/silencing-religiousstudents-on-campus/ 497951 (accessed 14 January 2018).

Lothian, A. (2016). 'Choose not to warn: Trigger warnings and content notes from fan culture to feminist pedagogy', Feminist Studies, 42:3, pp. 743-56.

Marcotte, A. (2013). 'The year of the trigger warning', Slate (30 December), www. slate.com/blogs/xx_factor/2013/12/30/trigger_warnings_from_the_feminist_ blogosphere_to_shonda_rhimes_in_2013.html (accessed 17 December 2017).

Muñoz, J. E. (1999). Disidentifications: Queers of Color and the Performance of Politics. Minneapolis: University of Minnesota Press.

O'Neill, B. (2015). 'Never mind Rhodes - it's the cult of the victim that must fall', Spiked (28 December), www.spiked-online.com/newsite/article/never-mindrhodes-its-the-cult-of-the-victim-that-must-fall/17762\#.WxZkVO6FPIU (accessed 4 June 2018).

Paasonen, S. (2015). 'A midsummer's bonfire: Affective intensities of online debate', in K. Hillis, S. Paasonen and M. Petit (eds), Networked Affect. Cambridge, MA: MIT Press, pp. 27-42.

Phipps, A. (2016). 'Whose personal is more political? Experience in contemporary feminist politics', Feminist Theory, 17(3), pp. 303-21.

Serano, J. (2014). 'Regarding "generation wars": Some reflections upon reading the recent Jack Halberstam essay', Whipping Girl blog (13 July), http://juliaserano. blogspot.fi/2014/07/regarding-generation-wars-some.html (accessed 14 January 2018).

Shildrick, M. (2002). Embodying the Monster: Encounters with the Vulnerable Self. London: Sage.

Souza, V. M. (2014). 'Triggernometry', It's Complicated blog (21 May), http:// valeriamsouza.wordpress.com/2014/05/21/triggernometry (accessed 1 June 2015).

Tyler, I. (2007). 'The selfish feminist: Public images of women's liberation', Australian Feminist Studies, 22:53, pp. 173-90.

Valk, A. M. (2008). Radical Sisters: Second Wave Feminism and Black Liberation in Washington, D.C. Chicago: University of Illinois Press.

Vigliano, A. (2014). 'How the "trigger warning" took over the internet', BuzzFeed (5 May), www.buzzfeed.com/alisonvingiano/how-the-trigger-warning-took-overthe-internet?utm_term=.bukOOAxb9\#.cbXNNly1n (accessed 17 December 2017).

Waldman, K. (2016). 'The trapdoor of trigger words: What the science of trauma can tell us about an endless campus debate', Slate (5 September), www.slate.com/articles/double_x/cover_story/2016/o9/what_science_can_tell_us_about_trigger_ warnings.html (accessed 14 January 2018).

Washick, B. (2017). 'An "app" for that: The case against the "equal access" argument for trigger warnings', in E. J. M. Knox (ed.), Trigger Warnings: History, Theory, Context. Lanham: Rowman \& Littlefield, pp. 86-120.

Williams, L. (1989). Hard Core: Power, Pleasure, and the 'Frenzy of the Visible'. Berkeley: University of California Press. 